\title{
AIS Transactions on Human-Computer Interaction
}

\section{Decision Confidence and Purchase Intention in Software Trials: A Cognitive Stopping Rule Perspective}

\author{
Xue Yang \\ Nanjing University, yangxue@nju.edu.cn \\ Shu Schiller \\ Wright State University - Main Campus, shu.schiller@wright.edu \\ Hock-Hai TEO \\ National University of Singapore, teohh@comp.nus.edu.sg \\ Quansheng Wang \\ Nanjing University, wangqs@nju.edu.cn
}

Follow this and additional works at: https://aisel.aisnet.org/thci

\section{Recommended Citation}

Yang, X., Schiller, S., TEO, H., \& Wang, Q. (2017). Decision Confidence and Purchase Intention in Software Trials: A Cognitive Stopping Rule Perspective. AIS Transactions on Human-Computer Interaction, 9(2), 123-148. Retrieved from https://aisel.aisnet.org/thci/vol9/iss2/3

DOI:

This material is brought to you by the AIS Journals at AIS Electronic Library (AISeL). It has been accepted for inclusion in AIS Transactions on Human-Computer Interaction by an authorized administrator of AIS Electronic Library (AISeL). For more information, please contact elibrary@aisnet.org. 


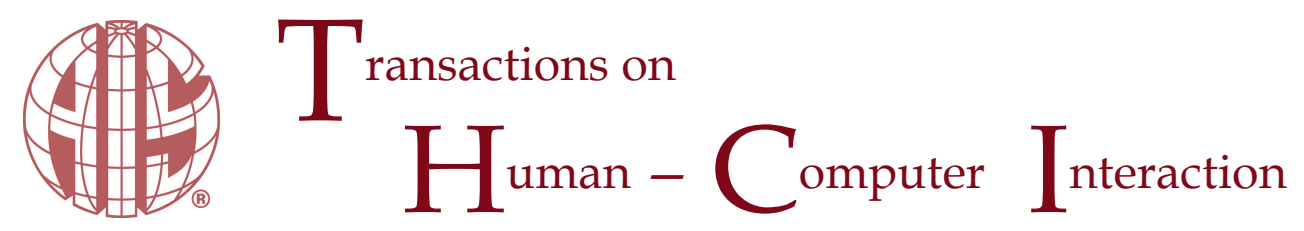

Research Paper

\title{
Decision Confidence and Purchase Intention in Software Trials: A Cognitive Stopping Rule Perspective
}

\author{
Xue Yang \\ Nanjing University, China \\ Hock Hai Teo \\ National University of Singapore, Singapore
}

\author{
Shu Schiller \\ Wright State University, USA \\ Shu.Schiller@wright.edu \\ Quansheng Wang \\ Nanjing University, China
}

\begin{abstract}
:
Organizations often offer software trials to potential buyers as a form of promotion. The trial experience provides firsthand information of the product, which contributes to prudent purchase decisions. Despite the popularity of software trials in consumer markets, we have yet to fully understand how individuals formulate purchase decisions throughout the trial process. This study proposes a novel perspective by focusing on 1) decision confidence that individuals establish when using a software trial based on the compatible cognitive stopping rules (CSRs) they apply and 2) the influence of decision confidence on purchase intention. We conducted a controlled lab experiment in which 204 participants tried an interior design software product. We found that the participants formed their decision confidence by applying compatible CSRs during the software trial. Decision confidence augmented the positive influence of product satisfaction on purchase decision. Interestingly, decision confidence attenuated the positive relationship between a user's satisfactory trial experience and the decision to purchase the software. We provide detailed discussions on our findings, limitations, theoretical contributions, and implications for practice.
\end{abstract}

Keywords: Software Trial, Purchase Intention, Decision Confidence, Cognitive Stopping Rules, Satisfaction.

The manuscript was received 01/22/2016 and was with the authors 6 months for 3 revisions. 


\section{Introduction}

Individuals most derive the value of intangible IT applications, such as software products, through direct individual usage (Jiang \& Benbasat, 2007). Thus, users commonly test commercial software before purchasing it and commit to such software for a long time (Cheng \& Liu, 2012; Wang, Oh, Wang, \& Yuan, 2013). Vendors often use free trials to promote their products and create sales leads (Adya \& Francis, 2011; Lee \& Tan, 2013) with the hope that the free software trials will trigger word-of-mouth marketing and increase product sales (Kempf, 1999). Organizations normally offer a software trial with various types of restrictions such as limited functionality or features (Cheng \& Liu, 2012; Dey, Lahiri, \& liu, 2013), restricted processing function (for instance, file size limit), output restrictions (such as inability to do so at all), or an expiration date for the trial (Yang \& Teo, 2007; Yang, Teo, \& Tan, 2006). Nonetheless, the personal interactions during the trial provide first-hand information about the product, which helps one make prudent purchase decisions (Smith \& Swinyard, 1988).

Some research suggests that offering a software trial can increase sales of the full-version software (Cheng \& Tang, 2010; Jiang, 2010; Wang \& Zhang, 2009) by reducing users' product uncertainties (Gallaugher \& Wang, 2002) and establishing their belief about the product (e.g., its quality or value) (Kempf, 1999). However, contrary to the expected outcome that software product trials should increase sales, in reality, the actual purchase rate after the trial is extremely low. For instance, the industry average download-to-purchase conversion ratio for downloadable software is one percent (Successful Software, 2009). In an attempt to solve this puzzle, scholars have studied how certain features of software trials can create positive outcomes. Tu and Lu (2006) found that providing a sample of music product increases its digital music downloads. Schlereth, Barrot, and Skiera, (2013) examined the effects of optimal product sampling strategies for product trials and found that the use of social network information significantly increases product purchases.

Despite the effort in the research on product trials, research has directed little attention toward understanding how the trial experience influences purchase decisions. In this study, we investigate how a user employs different trial strategies to evaluate software and how the choice of the strategy (or strategies) may further influence the decision making. In particular, we focus on decision confidence that individuals develop based on cognitive stopping rules (CSRs) when using a trial version to evaluate a software program's performance. We treat decision confidence as the underlying mechanism to uncover how individuals make purchase decisions based on their trial experience. We also believe that cognitive stopping rules (CSRs) hold the key to the interplay of trial strategies and the software trial task. Thus, -we ask:

RQ1: How is decision confidence in software trials established through individuals' applying cognitive stopping rules?

RQ2: How does decision confidence influence a user's purchase intention?

This paper proceeds as follows: in Section 2, we discuss the literature and theoretical background. In Section 3, we present the research framework and hypotheses. In Section 4, we present the research methodology applied in this study. In Section 5, we present the data analysis results. In Section 6, we discuss our findings and this study's contributions and limitations. Finally. In Section 7, we conclude the paper.

\section{Literature Review and Theoretical Background}

\subsection{Decision Confidence}

Decision confidence refers to a person's belief in the quality of a decision (Kasper, 1996) and relates to the likelihood of having done something correctly or incorrectly (Vickers, 1979; Yeung \& Summerfield, 2012). Decision confidence is an important aspect of subjective experience during decision making and a key indicator of the quality of decision performance (Pleskac \& Busemeyer, 2010). It can affect individual behaviors such as commitment to choices, purchase patterns (Chernev, 2009), and decision satisfaction (Shafir, Simonson, \& Tversky, 2000). Thus, decision confidence is a fundamental and ubiquitous component of decision making (Kepecs, Uchida, Zariwala, \& Mainen, 2008).

Through the psychological lens, decision confidence is related to the concept of uncertainty reduction (Hansen, 1972; Meyer \& Sathi, 1985). In general, when uncertainties decrease, the confidence for better 
decision making grows (Smith, Benson, \& Curley, 1991; Smith \& Swinyard, 1982). For example, compared to viewing an advertisement of a dishwasher soap pods, physically trying the soap allows consumers to directly experience the product, which may reduce their skepticism and hesitancy about, for instance, how effective the soap is and how good it smells. As a result, the trial generates confident affects, such as attitude ("I like this dish soap") and beliefs, such as acceptance ("It works") or rejection ("It does not work"). In other words, because the experience of product trial reduces the consumers' uncertainty about the product, it makes them more certain of their evaluation of the product's features than if they had not tried the product at all (Smith et al., 1991; Smith \& Swinyard, 1982).

Decision confidence is a critical factor in task performance. Decision making is a common task and often needs to be carried out in ambiguous, unfamiliar, and complex situations (Beach \& Mitchell, 1978). Individuals build decision confidence through searching for and evaluating information to gain a desired level of certainty about the quality of a decision (Hausmann \& Läge 2008). In a situation with unfamiliar and complex tasks, individuals use various information search strategies to collect information that adds to the validity of the earlier information (Hausmann \& Läge, 2008) and decreases the cognitive dissonance associated with the uncertainty (Ross \& Shulman, 1973), both of which then heighten their decision confidence (Hausmann \& Läge, 2008).

Using appropriate decision strategies is the key to decision confidence in decision making tasks. Previous research has found that compatible strategies with the decision task at hand lead to higher decision confidence, decision confirmation (Tan, Tan, \& Teo, 2012), and decision comfort (Parker, Lehmann, \& Yi, 2016). For instance, the amount and strength of evidence that supports the chosen option positively affects the subjective decision confidence (Koriat, Lichtenstein, \& Fischhoff, 1980). Scholars suggest that one can achieve such compatibility by matching a decision maker's product knowledge and information search strategy (Rathnam, 2005), fitting the regulatory focus and decision strategy (Wan, Hong, \& Sternthal, 2009; Yang, Schiller, Teo, \& Wang, 2010), or having consistency between the decision target and information processing strategies (Wang \& Liu, 2014).

On the other hand, decision confidence can be clouded by some individual and situational factors. For instance, Fischer and Budescu (2005) conducted an experiment with 1,200 decisions and found that the development of confidence depends on individuals' decision modes reflected in the representation of information and how the feedback is provided. Decision confidence can also depend on what decision rules one uses to evaluate an individual's judgments (Hill, 2013). An individual's decision confidence generally increases when their assessment of information for decision making is certain (Heereman \& Walla, 2011) and decreases when uncertain. Scholars note that these factors may prevent an individual from searching for and processing more information; thus, one may not reach the desired level of confidence at all.

We also note that decision confidence may not always reflect decision accuracy or quality. Individuals sometimes can feel overconfident or underconfident about a decision depending on how they make it (Koriat et al., 1980; Kvidera \& Koutstaal 2008; Moore, Carter, \& Yang, 2015). Individuals could also improve the confidence level through additional support such as receiving affirmation on the decision from others (Sharp, Cutler, \& Penrod, 1988; Yates, 1990). Lack of experience or expertise could also lead to overconfidence in laypersons or novices due to their inability to make a right judgment on the quality of the decision outcome (Yates, 1990). Borrowing an old saying, if we do not know what we do not know, we cannot make adequate judgments.

Based on the above discussion on the key insights of decision confidence and its determining factors and how they relate to the software trial task, we believe that taking an appropriate decision making strategy that matches the characteristics and objectives of the task of question is the key to individuals' making confident decisions. Among various types of decision making strategies, we notice that "information search is a fundamental activity in problem solving and decision making" (Browne, Pitts, \& Wetherbe, 2007, p. 98). During a software trial, one or more information search strategies guide users in evaluating the software's functions, determining its quality, and making a purchase decision. Thus, in this study, we focus on the information search strategy as a determinant to decision confidence and particularly apply CSRs to represent the information search strategy that a user can take in evaluating a software trial.

\subsection{CSRs as Information Search Strategies}

CSRs can serve as a type of heuristics for decision making because, based on CSRs, users can stop searching for more information when they reach the best point to make a decision with sufficient 
information about a product (Browne et al., 2007). Intuitively, for a search to stop, one must have initiated it at some point and it must have been in motion before being stopped. Thus, we argue that the functions of CSRs go beyond just stopping searches but, more importantly, channel and guide users' attention and cognitive processing of information during searches before stopping them. Previous research shows that individual use CSRs during different stages of decision making, including searching for information in the early stages and making choices in the later stages (Browne \& Pitts, 2004). Guided by CSRs, participants need to search and collect information, process it, reason about it, and judge the adequacy and sufficiency of it (Browne et al., 2007). These activities clearly go beyond just the cognitive stopping (a point) but with also guiding the searching (motion) in the decision making process.

To explain this further, we note that CSRs are a type of heuristics for decision making that are comparable to a set of information collection and integration strategies (Goldstein \& Gigerenzer, 1999). CSRs play a major role in decision making by channeling what information people search for and then stopping the search when they are confident enough to make a decision. In other words, we can look at CSRs as strategies for directing the information people search for either consciously or subconsciously and, more critically, as subjective heuristics to stop searching. In this research, we use CSRs to conceptualize when and how the information search stops.

There are five most common CSRs: 1) the mental list rule, 2) single criterion rule, 3) magnitude threshold rule, 4) representational stability rule, and 5 ) difference threshold rule (Table 1). These five CSRs involve reasoning and judgment regarding the decision maker's information search outcomes (Browne et al., 2007). Individuals use a particular stopping rule to determine at which point they have accumulated sufficient information to make a decision (Hausmann \& Läge, 2008), and, thus, they stop searching. The extant literature suggests that individuals use different decision heuristics for different classification schema. Simple stopping rules are tailored to one-reason decision making and sequential information search (Gigerenzer \& Todd, 1999). Some stopping behaviors are based on the probability of correct predictions (Hausmann \& Läge, 2008), marginal costs of searching more compared to the marginal benefits (Lippman \& McCall, 1976), or the total return from the search (Kogut, 1990). Other stopping rules are based on the cost of making a terminal decision that is no more than the sum of the costs of seeking additional evidence (Busemeyer \& Rapoport, 1988). There are also stopping rules particularly formulated for searching for nonsequential information (Stigler, 1961).

Table 1. Cognitive Stopping Rules (Adapted from Browne et al., 2007)

\begin{tabular}{|c|c|c|}
\hline Rule & Definition & Compatible with software trial task? \\
\hline Mental list & $\begin{array}{l}\text { People have a mental list of items that they must satisfy } \\
\text { before they will stop collecting information. }\end{array}$ & No \\
\hline Single criterion & $\begin{array}{l}\text { People decide to search for information related to a } \\
\text { single criterion and stops when they have enough } \\
\text { information about that criterion. }\end{array}$ & No \\
\hline $\begin{array}{l}\text { Magnitude } \\
\text { threshold }\end{array}$ & $\begin{array}{l}\text { People have a cumulative amount of information that } \\
\text { they need before they will stop searching. The focus is } \\
\text { on having "enough" information. }\end{array}$ & Yes \\
\hline $\begin{array}{l}\text { Representational } \\
\text { stability }\end{array}$ & $\begin{array}{l}\text { People search for information until their mental model, } \\
\text { or representation, stops shifting and stabilizes. The } \\
\text { focus is on the stability of the representation. }\end{array}$ & Yes \\
\hline $\begin{array}{l}\text { Difference } \\
\text { threshold }\end{array}$ & $\begin{array}{l}\text { People sets an a priori difference level to gauge when } \\
\text { they are not learning anything new. When they stop } \\
\text { learning new information, they stop searching for } \\
\text { information. }\end{array}$ & $\begin{array}{l}\text { Neither compatible nor incompatible } \\
\text { according to the original CSR theory; } \\
\text { thus, we eliminated it from further } \\
\text { investigation in this study. }\end{array}$ \\
\hline
\end{tabular}

To illustrate, we can consider the earlier example where an individual tries a new dishwasher soap pods (let us call this individual Sarah). If Sarah knows the desired features such as tough grease removal on all types of surfaces and shiny finish of dishes, she can consciously apply the mental list stopping rule, which guides her to decompose the trial task to examine each feature. She would notice how the pod detergent removes grease on dishes and pans. She would also pay attention to the finish after the dishes are done. Thus, she reviews information of this new dishwasher pod guided by the mental list stopping rule to focus on those two attributes. On the other hand, her search strategy would function very differently if she 
applied a different stopping rule. In this case, the situation could be that she has never used dishwasher pods before. She knows subconsciously that she cannot search indefinitely, so she would review the new product and mentally register information about the product. She may notice any possible suds, the cleanness of the dishes and cooking pans, and the smell and finish of the dishes. In this case, she tries to gain a sense of the new product and develop an adequate representation of the new product. She needs to interpret the sound and visual information such as how the pods work in the dishwasher and comprehend the new ways this product works that differ from her previous experiences. Her information searching stops when she believes that she has gained "enough" information or she feels that she has achieved sufficient confidence to make her purchase decision. In this case, the use of the magnitude threshold rule guides her to search information in different ways than if she were using, for instance, the mental list rule.

\subsection{Compatible CSRs for Software Trial Tasks}

Compatibility of CSRs is an important factor in task performance because people use different CSRs when performing different tasks (Browne \& Pitts, 2004; Browne et al., 2007). Particularly, CSRs do not emphasize the sequence or the cost/benefit of information search and, therefore, are suitable for information search tasks such as software trials that do not necessarily involve choices among alternatives. In this study, we particularly emphasize the role of compatibility between the nature of the information search strategy and the characteristics of the task in determining the effectiveness of any CSR being applied (Davies, 2003; Morera \& Budescu, 1998; Porter, 2004). Compatibility between the stopping rules and the task can enhance the sense of self-assurance (Kruglanski, 2006) and heightens confidence in decision making (Aaker \& Lee, 2006; Avnet \& Higgins, 2006). For example, when there is a fit between the decision making task and the cognitive strategy used, people regard their reactions to the task as appropriate and become more confident in their decision making outcomes (Chernev, 2004; Dhar, 1997; Duan, Gu, \& Whinston, 2009).

Much previous research on task elements has introduced a task structure that distinguishes tasks as well structured or loosely structured (Browne et al., 2007). The five common CSRs we introduce above are also either decomposable or holistic in nature. Thus, some CSRs suit well-structured tasks and others suit loosely structured tasks. Well-structured tasks involve relatively clear objectives and decomposable steps for achieving the objectives. Research considers decomposable CSR strategies (mental list rule or single criteria rule) a good match with such tasks because one can separate its individual elements for cognitive representation and processing (Browne \& Pitts, 2004). In contrast, loosely structured tasks involve general objectives and lack specific guidance on information search directions. Thus, holistic CSR strategies (magnitude threshold or representational stability) are more compatible to ensure one reaches a reasonable confidence level (Browne \& Pitts, 2004).

Based on our previous discussion on task elements, we hold the assumption that a software trial is a complex and loosely structured information search task because software trials have high complexity and, in many cases, people have little or no experiences with the software, which is why they want to try it. Recent applications of CSRs demonstrate that, for loosely structured tasks (high complexity), holistic CSRs (magnitude threshold and representational stability rules) are more compatible than the other types of CSRs (Browne et al., 2007), which Table 1 shows. We believe that holistic CSRs heighten a user's confidence in evaluating the software trial evaluation related to the outcome of making a purchase decision.

To put things into perspective, we illustrate how magnitude threshold and representational stability rules work for software trial tasks. Consider an example when a user, John, evaluates a new photo editing software program. John knows in general that he is looking for various features to edit images. But the trial task is rather complex to him because he is not familiar with photo editing software and cannot easily decompose the task into smaller, incremental portions and items. Rather, he wants to at least make sense of the software and obtain some gist of what it does and how it works. Thus, his interaction with the software needs to provide just enough information to develop an adequate representation of the photo editing functions. He may first examine the major overall features of the software and then try different options of a specific feature such as the exposure correction or resizing. While he tries the software, he starts to gain sense of its functions, understand its features, reason about its design, and judge the strengths and weaknesses of the software. At one point, he feels that he has gathered enough information (magnitude threshold rule) or his representation of the software stabilizes (representation stability rule). At this moment, the CSRs suggest that he stop the search. Thus, the magnitude threshold and 
representational stability rules, which both emphasize a certain level of information quantity, are a good match for such software trial task.

\section{Research Model and Hypothesis Development}

By leveraging the literature, we developed three hypotheses to examine the interplay between CSRs, decision confidence, and post-trial purchase intentions for software.

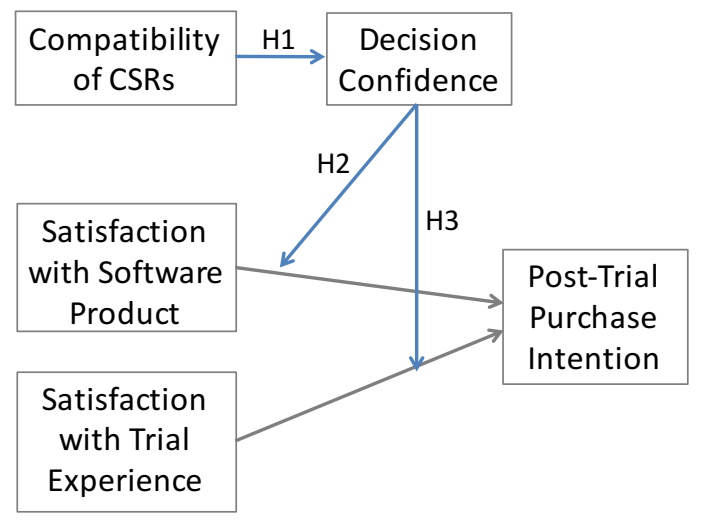

Figure 1. Research Model

\subsection{Decision Confidence and CSR Compatibility}

One can conceptualize decision confidence based on the notion of uncertainty and, more precisely, the reduction of uncertainty. When evaluating the product, users seek information to reduce uncertainty about that product to raise their confidence level in their decisions (Hansen, 1972; Meyer \& Sathi, 1985). Thus, decision confidence can reflect how effectively a user applies CSRs for seeking information during the trial (Buchanan \& O'Connell, 2006; Goodwin, 2009; Heitmann, Lehmann, \& Hermann, 2007; Wan et al., 2009). CSRs function differently with different types of tasks. Above, we mention how some CSRs (including representational stability and magnitude threshold) emphasize information quantity and work well with ambiguous or complex tasks (Browne et al., 2007). And other CSRs (mental list or single criterion) work well with tasks that have decomposable guidelines or clear processing structures.

Evaluating the trial version of a software program is primarily a complex judgment task that demands a significant amount of knowledge and number of skills and resources from the task performer (Wood, 1986). A user who tries the software is most likely a first-time user and not experienced in the particular software (Pitts \& Browne, 2004). The software trial requires the user to significantly explore and evaluate many of its different aspects and functions (Vakkari, 1999) in order to obtain enough knowledge and skills about it. The software trial task also demands a significant amount of resources including focus, time, cognitive absorption, and processing. Thus, the software trial involves a large number of distinct actions that one needs to execute and unique information cues that one needs to process in performing those actions, which greatly increase the task's complexity (Wood, 1986). It is difficult for an inexperienced user to form a clear single criterion or a structured mental list to evaluate software. In contrast, representational stability and magnitude threshold CSRs are holistic in nature and more compatible with ambiguous or complex tasks with little experience (Browne et al., 2007). These CSRs allow users to freely explore the software until the trial experience reaches a certain level of sufficiency. When uncertainly reduces, individuals' confidence surfaces and they can make informed and trusting decisions.

In sum, the compatibility between CSRs and the software trial task will impact a user's confidence on the post-trial purchase decisions. When individual use compatible CSRs in a software trial task, they experience the strength of evidence that supports their decision, which, in turn, develops positive feelings that affect their subjective decision confidence (Koriat et al., 1980). Therefore, users who perceive that their CSRs are more compatible with a software trial task will be more confident with the decision made. We propose: 
H1: During a software trial, users have a higher decision confidence when they apply compatible CSRs (magnitude threshold and/or representational stability) than when they apply other incompatible CSRs (mental list and/or single criterion).

\subsection{Decision Confidence and Purchase Intention}

Decision confidence is an important factor that affects decision outcomes (e.g., purchase intention). In a product evaluation task that Avnet and Higgins (2003) and Higgins, Idson, Freitas, Spiegel, and Molden (2003) studied, people were willing to pay more for a product when their choice strategies fit their process goal orientations compared to when the strategies did not match their goals. In other words, how well a person's current strategy (e.g., a particular CSR) suits the goals of the task (e.g., software trial task) is meaningful to that person's decision making.

The literature suggests that a user's perceived satisfaction level with a product and the user's experience in personally using that product (which might function unconsciously) affect the user's purchase intention (Kruglanski, 2006). First, empirical studies in both IS and marketing have shown that product satisfaction, which refers to a user's feelings or attitude toward a product, is critical to their purchase decisions (Bolton \& Lemon, 1999; Chandrashekaran, Rotte, Tax, \& Grewal, 2007; Mittal \& Kamakura, 2001; Wixom \& Todd, 2005). Second, satisfaction with a trial experience reflects the positive attitude individuals form as a result of pleasant trial experiences with a product, which research has also found to be critical to purchase decisions (McKinney, Yoon, \& Zahedi, 2002). A satisfying trial experience is more likely to positively influence the purchase decision (Everard \& Galletta, 2005).

According to the theory of self-perception (Bem, 1967), raising the salience of an existing attitude by either confirming or disconfirming the attitude's legitimacy may increase or decrease cognitive dissonance associated with the attitude (e.g., reflected in the change of attitude) (Ross \& Shulman, 1973). Thus, decision confidence acts as a stimulus that reminds an individual to further judge the congruence of a follow-up decision with the general attitude formed. In other words, high decision confidence motivates people to make congruent decisions based on their existing attitudes, but low decision confidence implies greater cognitive dissonance. Thus, decision confidence affects the relationship between the attitude and the eventual decisions they make. People who are uncertain about their choices or decisions may face greater difficulty when making a purchase decision, which would weaken the influence of individuals' satisfaction with a product and satisfaction with the trial process on their decision making (Dhar \& Nowlis, 1999). Based on the above theoretical arguments, we propose that a user's decision confidence on the decision the user chooses to make enhances the relation between satisfaction (with both the product and the trial experience) and purchase intention:

H2: Decision confidence has a positive moderation effect on the relationship between a user's satisfaction with a software product and the post-trial purchase intention; that is, when a user has a higher decision confidence, the user's satisfaction with the software product is more likely to lead to a higher post-trial purchase intention.

H3: Decision confidence has a positive moderation effect on the relationship between a user's satisfaction with the trial experience and the post-trial purchase intention; that is, when a user has a higher decision confidence, the user's satisfaction with the trial experience is more likely to lead to a higher post-trial purchase intention.

\section{Research Methodology}

\subsection{Research Design and Data Collection}

To test the research hypotheses, we designed a controlled lab experiment to capture the trial strategies individuals used, their decision confidence, and their purchase intentions. To ensure that all participants were exposed to the same software trial and to avoid any bias of individual software interests or preferences, we employed a scenario-based controlled laboratory experiment, which we believe was the most appropriate and realistic approach to test our research hypotheses.

IS studies have widely adopted the scenario-based approach. Scenarios are carefully developed situations to describe "how the world will be" and "reflect the logical implications of assumptions and forecasts about what the future will be like" (Gray \& Hovav, 2008, p. 219). Through scenarios, one can examine issues to allow people to adjust to "their changing environments" and choose actions to resolve 
future issues (Gray \& Hovav, 2008, p. 219). For example, researchers can require participants to imagine that they are in an online shopping environment to purchase some particular products that they need and ask them to perform some shopping tasks and answer questions based on this scenario (Benlian, Titah, \& Hess, 2012). Previous research shows that "the use of written scenarios is a suitable methodology for theory testing as long as participants are confronted with situations that are realistic and that they experience on a regular basis" (Wehner, Giardini, \& Kabst, 2012, p. 608).

Following these guidelines, we developed a scenario to evaluate the trial version of an office interior design software program. Participants had to use the trial version to design their office workspace before making purchase decisions. We chose online interior design software for this study because of its popularity for planning and designing home and office spaces; it enables one to design and visualize a space in virtual reality before spending on renovations. CNET's website lists over 1,000 different interior design software applications. Many retailers, such as IKEA, provide design software that allows their customers to plan and design a space using their product range before making a purchase.

As for our experiment procedure, we recruited student participants from two large universities in metropolitan areas in the USA and China. We invited each participant through email and online channels. We selected participants who indicated that they had never used interior design software. Each participant received a detailed description of the scenario that they needed to evaluate an interior design software, 3D Spacer. The software provided precise 2D arrangement and realistic 3D visualization of interiors. We provided the basic information of the software and detailed instructions of how to use it. We then informed the participants that the online software was available in full for a 15-day trial period, after which one had to pay a premium to continue using it. Next, we asked the participants to follow the instructions and use 3D Spacer to design an office space that they found favorable. Once finished, the participants submitted their designs for evaluation. In the end, we directed the participants to the survey website to answer the survey questions. Each participant received US\$5 in cash or a gift card as the compensation for participation. The Appendix shows the interface of the software and the selected designs from participants. In total, we recruited 204 participants. After removing incomplete data points, we retained 193 data points for further analysis. Table 2 shows participants' demographic information.

Table 2. Descriptive Statistics

\begin{tabular}{|c|c|c|c|c|c|c|c|}
\hline $\begin{array}{l}\text { Demographic } \\
\text { variable }\end{array}$ & Category & \multicolumn{2}{|c|}{ Frequency (\%) } & Demographic variable & Category & \multicolumn{2}{|c|}{ Frequency (\%) } \\
\hline \multirow{2}{*}{ Gender } & Male & 108 & $56 \%$ & \multirow{5}{*}{ Age } & $18-20$ & 34 & $17.6 \%$ \\
\hline & Female & 85 & $44 \%$ & & $21-24$ & 119 & $61.7 \%$ \\
\hline \multirow{4}{*}{$\begin{array}{c}\text { Highest level of } \\
\text { education / highest } \\
\text { degree }\end{array}$} & High school & 81 & $42.0 \%$ & & $25-29$ & 29 & $15.0 \%$ \\
\hline & Bachelor & 92 & $47.7 \%$ & & $30-34$ & 3 & $1.6 \%$ \\
\hline & Master & 14 & $7.3 \%$ & & $>34$ & 8 & $4.1 \%$ \\
\hline & Doctorate & 6 & $3.1 \%$ & \multirow{5}{*}{$\begin{array}{l}\text { Years of Internet } \\
\text { experience }\end{array}$} & $<6$ & 12 & $6.2 \%$ \\
\hline \multirow{6}{*}{$\begin{array}{l}\text { Number of different } \\
\text { trial software programs } \\
\text { tested before this } \\
\text { experiment }\end{array}$} & None & 4 & $2.1 \%$ & & $6-10$ & 121 & $62.7 \%$ \\
\hline & 1 to 2 & 33 & $17.1 \%$ & & $11-15$ & 53 & $27.5 \%$ \\
\hline & 3 to 4 & 35 & $18.1 \%$ & & $16-20$ & 4 & $2.1 \%$ \\
\hline & 5 to 6 & 39 & $20.2 \%$ & & $>20$ & 3 & $1.6 \%$ \\
\hline & 7 to 10 & 24 & $12.4 \%$ & \multirow{2}{*}{$\begin{array}{l}\text { Post-trial software } \\
\text { purchase experience } \\
\text { before this experiment }\end{array}$} & Yes & 28 & $14.5 \%$ \\
\hline & $\begin{array}{c}11 \text { to } 14 \\
15 \text { or above }\end{array}$ & $\begin{array}{l}13 \\
45\end{array}$ & $\begin{array}{l}6.7 \% \\
23.3 \%\end{array}$ & & No & 165 & $85.5 \%$ \\
\hline
\end{tabular}




\subsection{Construct Measures}

We adapted measures for product satisfaction, trial experience satisfaction, decision confidence, and purchase intention from validated items used in previous studies (Table 3). We pilot-tested our measures using sixteen information systems (IS) students (eight undergraduates and eight graduates). We conducted two pilot-testing sessions in which participants sorted measurement items to their corresponding constructs: one session with labeled measurement items and the other with unlabeled measurement items. We made minor modifications to the measurement items to address the concerns these students raised and to ensure that the survey instrument was clear and easy to understand. We randomized the order of the survey items to minimize common method variance due to the measurement context issue (Podsakoff, MacKenzie, Lee, \& Podsakoff, 2003).

Table 3. Operationalization of Constructs

\begin{tabular}{|c|c|c|}
\hline Construct & Items & Scale and source \\
\hline $\begin{array}{l}\text { Product } \\
\text { satisfaction } \\
\text { (product) }\end{array}$ & $\begin{array}{l}\text { Please rate to what extent you agree with each of the } \\
\text { following statements. } \\
\text { I am satisfied with the software I have just tested. } \\
\text { I am pleased with the software I have just tested. } \\
\text { I am happy with the software I have just tested. }\end{array}$ & $\begin{array}{c}\text { (Mittal \& Kamakura, 2001) } \\
\text { 7-point Likert scale (strongly disagree } \\
\text { to strongly agree) }\end{array}$ \\
\hline $\begin{array}{l}\text { Trial experience } \\
\text { satisfaction } \\
\text { (experience) }\end{array}$ & $\begin{array}{l}\text { Overall, how do you feel about this trial experience? } \\
\text { The overall trial experience is pleasant. } \\
\text { The overall trial experience is helpful. } \\
\text { The overall trial experience is engaging. } \\
\text { The overall trial experience is enjoyable. }\end{array}$ & $\begin{array}{c}\text { (Daugherty, Li, \& Biocca, 2008) } \\
\text { 7-point Likert scale (strongly disagree } \\
\text { to strongly agree) }\end{array}$ \\
\hline $\begin{array}{l}\text { Decision } \\
\text { confidence } \\
\text { (confidence) }\end{array}$ & $\begin{array}{l}\text { When you made a decision to buy/not buy the software, } \\
\text { how confident were you about the decision made? } \\
\text { Please rate to what extent you agree with each of the } \\
\text { following statements. } \\
\text { I am confident in my ability to make the right purchase } \\
\text { decision to buy/not buy this software. } \\
\text { I am certain about my decision to purchase/not } \\
\text { purchase) this software. } \\
\text { I am sure I will make the right decision related to } \\
\text { purchasing/or not purchasing) this software. }\end{array}$ & $\begin{array}{c}\text { (Krishnan \& Smith, 1998) } \\
\text { 7-point Likert scale (strongly disagree } \\
\text { to strongly agree) }\end{array}$ \\
\hline $\begin{array}{l}\text { Purchase } \\
\text { intention } \\
\text { (purchase) }\end{array}$ & $\begin{array}{l}\text { Assuming that price is not an issue, what is your } \\
\text { decision on the purchase of the software? Please rate to } \\
\text { what extent you agree with each of the following } \\
\text { statements. } \\
\text { The likelihood that I will purchase this software is high. } \\
\text { The probability that I will buy the software is high. } \\
\text { It is very likely that I will buy this software. }\end{array}$ & $\begin{array}{c}\text { (Laroche, Kim, \& Zhou, 1996) } \\
\text { 7-point Likert scale (strongly disagree } \\
\text { to strongly agree) }\end{array}$ \\
\hline
\end{tabular}

We coded the construct "compatibility of CSRs" as a categorical variable with three values: compatible, incompatible, and neutral. We determined the values based on whether an individual applied the right type of information searching strategy during a trial process in a two-step process. First, we detected each CSR used based on the definitions and examples provided in Browne et al. (2007) (Table 4). To ensure the reliability and validity of our indicators, four IS faculty members and six IS postgraduates pilot-tested the measures by linking each indicator with the most representative CSR based on their theoretical definition. We then conducted face-to-face discussions to resolve disagreements regarding item categorization. We considered that we achieved agreement when the categorizations reached a satisfactory level (Cohen's kappa test showed that the value reached 87\%) (Cohen, 1960); thus, we validated the appropriateness of the CSR categorizations. We kept four indicators for each CSR as the manipulation check measure for the information searching rule applied in the experiment. During the experiment, we presented the items in each CSR category to participants in a random order to prevent confounding order effects. 
Table 4. Items to Verify CSRs

\begin{tabular}{|c|c|}
\hline CSR & Indicators (Adapted from Browne et al., 2007) \\
\hline Mental list & $\begin{array}{l}\text { 1. I continued testing the software until I finished testing all the functions I wrote in my } \\
\text { list. } \\
\text { 2. I stopped the software evaluation after I completed testing all the functions I was } \\
\text { interested in. } \\
\text { 3. I listed a few functions of the software and evaluated all of them before I stopped the } \\
\text { test. } \\
\text { 4. I continued assessing the software functions until I felt that I have learned all I want to } \\
\text { know about the software. }\end{array}$ \\
\hline Single criterion & $\begin{array}{l}\text { 1. I only had one criterion for the software (e.g., convenience in designing), and I } \\
\text { stopped testing when I had enough information about it. } \\
\text { 2. Before I stopped evaluating, I focused on one aspect of the software (e.g., } \\
\text { convenience in editing). } \\
\text { 3. I kept evaluating one aspect of the software (e.g., convenience in designing) before I } \\
\text { finished the test. } \\
\text { 4. I focused all my attention toward one aspect of the software (e.g., convenience in } \\
\text { designing) and finished the test when I had enough information. }\end{array}$ \\
\hline $\begin{array}{l}\text { Magnitude } \\
\text { threshold }\end{array}$ & $\begin{array}{l}\text { 1. I kept evaluating the software until I felt that I had enough information about it. } \\
\text { 2. I stopped evaluating the software only when I knew enough about it to make a } \\
\text { decision. } \\
\text { 3. I kept testing different functions of the software for more information until I felt that it } \\
\text { was enough. } \\
\text { 4. I continued testing different functions of the software until I felt that my knowledge of } \\
\text { the software was sufficient. }\end{array}$ \\
\hline $\begin{array}{l}\text { Representation } \\
\text { al stability }\end{array}$ & $\begin{array}{l}\text { 1. I kept testing the software until I felt that my judgment about the software performance } \\
\text { would not change anymore. } \\
\text { 2. I kept evaluating the software until my feeling about the software performance was } \\
\text { finalized. } \\
\text { 3. I stopped testing different functions of the software when I felt that more information } \\
\text { would not change my judgment about the software. } \\
\text { 4. I continued the software evaluation until I confirmed my conclusion about the software. }\end{array}$ \\
\hline
\end{tabular}

Second, we determined the compatibility between the CSR and the trial task. We found compatibility when individuals applied representational stability and/or magnitude threshold CSRs. In contrast, we found incompatibility when they applied mental list and/or single criterion CSRs. To explain the process in detail, after completing the interior design task, we asked participants to choose the indicators applied to their trial experience in the survey. For instance, if a participant marked the indicator "I continued testing the software until I finished testing all the functions I wrote in my list", it indicated that the individual used the mental list CSR during the experiment. For each participant, we counted the total number of indicators chosen for each CSR. If the largest number of indicators used were compatible CSRs (representational stability or magnitude threshold), we assigned a value of compatible. If the largest number of indicators used were incompatible CSRs (mental list or single criterion), we assigned a value of incompatible. If the numbers of indicators used for compatible and incompatible CSRs were equal, we assigned a value of neutral. We included the neutral category because people sometimes shift or mix their information search strategies if their objectives change during the dynamic trial process. In all, the three categories of compatible, incompatible, or neutral comprised 56.0, 35.8, and 8.2 percent of participants, respectively (Table 5). These results indicate that the majority of participants used compatible CSRs in their software trial. 
Table 5. Categorical Values of CSR Compatibility

\begin{tabular}{|c|c|c|}
\hline CSR compatibility & Participants (N = 193) & Percentage \\
\hline Compatible & 108 & $56.0 \%$ \\
\hline Incompatible & 69 & $35.8 \%$ \\
\hline Neutral & 16 & $8.2 \%$ \\
\hline
\end{tabular}

\section{Data Analysis and Results}

\subsection{Assessment of the Measurement Model}

Because our data was cross-sectional, we first performed a series of tests to rule out common method bias by following the methods suggested in Podsakoff et al. (2003). First, when administrating the survey, we exercised a procedural control by randomizing the order of the survey items. Second, we adopted the single-method factor approach, the best solution to address the common method variance issue in the current scenario because we could not obtain the predictor variables and dependent variables from different sources without knowing the source of the common method variance problem. Results showed that the common-method factor could only account for a relatively small proportion of the total variance $(24.5 \%)$. The results suggest that common-method variance was not a pervasive problem in this study.

We also conducted a multicollinearity test by assessing the variance inflation factors (VIFs) and tolerance values of the constructs. In general, the common rule for the presence of multicollinearity is that VIFs should be higher than 10 or that the tolerance values should be less than 0.1 . Our results indicated that the highest VIF was 2.326, significantly lower than the benchmark value of 10 , and the lowest tolerance value was 0.430 , higher than the benchmark value of 0.1 . Thus, multicollinearity did not appear to be a significant problem.

We then examined the reliability, convergent validity, and discriminant validity of the research model by using SmartPLS. The results were satisfactory compared with the recommended values that Gefen, Straub, \& Boudreau (2000) and Urbach and Ahlemann (2010) suggest. We assessed reliability by computing the Cronbach's alpha (proposed threshold value of 0.70 ) and the composite reliability (recommended threshold value of 0.70 ) of the constructs (see Table 6). We tested convergent and discriminant validity through confirmatory factor analysis and the computing of correlations between constructs, average variance extracted (AVE), and cross-loadings. As Table 6 shows, the factor loadings showed a strong correlation between each indicator and its corresponding construct, and the AVE for each construct exceeded 0.50 ; thus, we found satisfactory convergent validity. We evaluated discriminant validity by examining the cross-loadings of the indicators on other constructs. As Table 6 shows, the loading of each indicator was higher for its designated construct than for any other construct. Furthermore, the square root of the AVEs for each construct was greater than the inter-construct correlations for each construct (off-diagonal numbers) in all cases (Table 7). Thus, we conclude that discriminant validity for all constructs was supported as well. 
Table 1. Results of Convergent and Discriminant Validity Tests

\begin{tabular}{|c|c|c|c|c|c|c|c|c|c|c|}
\hline \multirow{2}{*}{$\begin{array}{l}\text { Constructs and } \\
\text { indicators }\end{array}$} & \multirow{2}{*}{ Mean } & \multirow{2}{*}{ SD } & \multirow{2}{*}{$\begin{array}{c}\text { Reliability } \\
\text { of } \\
\text { indicators }\end{array}$} & \multirow{2}{*}{$\begin{array}{c}\text { Cronbach's } \\
\text { alpha }\end{array}$} & \multirow{2}{*}{$\begin{array}{c}\text { Composite } \\
\text { reliability }\end{array}$} & \multirow{2}{*}{$\begin{array}{l}\text { Average } \\
\text { variance } \\
\text { extracted }\end{array}$} & \multicolumn{4}{|c|}{ Cross Loadings } \\
\hline & & & & & & & 1 & 2 & 3 & 4 \\
\hline Product & 4.85 & 1.283 & & .962 & .975 & .929 & & & & \\
\hline Product1 & & & 0.951 & & & & .329 & .269 & .852 & -.021 \\
\hline Product2 & & & 0.977 & & & & .358 & .283 & .861 & -.009 \\
\hline Product3 & & & 0.963 & & & & .433 & .264 & .810 & -.084 \\
\hline Experience & 5.17 & 1.167 & & .916 & .941 & .799 & & & & \\
\hline Experience1 & & & 0.899 & & & & .727 & .182 & .491 & .060 \\
\hline Experience2 & & & 0.918 & & & & .829 & .246 & .192 & .052 \\
\hline Experience3 & & & 0.851 & & & & .859 & .185 & .260 & .081 \\
\hline Experience4 & & & 0.906 & & & & .765 & .176 & .464 & .002 \\
\hline Confidence & 5.36 & 1.489 & & .912 & .945 & .851 & & & & \\
\hline Confidence1 & & & 0.902 & & & & .024 & -.063 & -.005 & .907 \\
\hline Confidence2 & & & 0.930 & & & & .051 & -.087 & -.035 & .918 \\
\hline Confidence3 & & & 0.935 & & & & .049 & -.080 & -.020 & .929 \\
\hline Purchase & 3.38 & 1.489 & & .961 & .975 & .928 & & & & \\
\hline Purchase1 & & & 0.962 & & & & .249 & .883 & .261 & -.107 \\
\hline Purchase2 & & & 0.972 & & & & .217 & .915 & .226 & -.087 \\
\hline Purchase3 & & & 0.955 & & & & .175 & .916 & .206 & -.097 \\
\hline
\end{tabular}

Table 2. Inter-construct Correlations

\begin{tabular}{|c|c|c|c|c|}
\hline & Product & Experience & Confidence & Purchase \\
\hline Product & .964 & & & \\
\hline Experience & .746 & .894 & & \\
\hline Confidence & -.030 & .095 & .922 & \\
\hline Purchase & .551 & .483 & -.200 & .963 \\
\hline
\end{tabular}

\subsection{Hypothesis Testing}

After establishing the validity of the measures, we assessed the hypotheses using SPSS, and Tables 8, 9, and 10 provide the results. We used six control variables, and five were not significant in influencing posttrial purchase decision (gender, age, years of Internet experience, number of software trials tested before this experiment, and prior post-trial purchase before this experiment). As a whole, the model explained 18.47 percent of the variance of purchase intention $\left(R^{2}=18.47 \%\right)$.

To test $\mathrm{H} 1$, we conducted a series of MANCOVA tests on the key variables by using the CSR groups as the independent variable and other variables as the dependent variables. We also included control variables. We found a significant difference for the construct of decision confidence (confidence) (between-group $F=4.443, p=.013$ ), which supported our argument that different CSR groups result in different levels of decision confidence (Table 8). Based on this preliminary result, we further identified the difference in decision confidence among the CSR groups. Because the equal variance assumption between the group means was satisfied for the decision confidence construct in Levene's test $(p>.05)$, we performed parameter estimation against the compatible CSR groups. The results showed that, compared to compatible CSRs, incompatible CSRs had a significant negative relationship with confidence $(\beta=-.503, p=.003$ ) (Table 9). In addition, the parameter estimation suggested that the effect of neutral CSRs on decision confidence was similar to that of separately applying compatible CSRs $(\beta=-.127, p$ $=.659$ ). To further verify the effects of CSRs, we performed three MACOVA analyses using product 
satisfaction, trial experience satisfaction, and purchase intention as the dependent variables. Results showed no significant relationship between CSRs and these variables, and only two control variables had significant relationships with some of the dependent variables (age and trial experience satisfaction, $\beta=$ $.284, p=.002$; education and purchase intention, $\beta=-.324, p=.033$ ). Thus, $\mathrm{H} 1$ was supported.

The moderating effect of decision confidence on the relationship between product satisfaction and purchase decision was positive and significant $(\beta=0.099, p=.01)$; thus, we found support for $\mathrm{H} 2$. Contradictory to what we propose in $\mathrm{H} 3$, decision confidence moderated the relationship between satisfaction with the trial experience and purchase decision $(\beta=-0.05, p=.05)$ but was negative in the opposite direction (Table 10).

Table 3. Descriptive Statistics and MANCOVA Tests (IV: CSR Group)

\begin{tabular}{|c|c|c|c|c|c|}
\hline Construct & CSR Group & Mean & SD & F Value & Sig. \\
\hline \multirow{4}{*}{$\begin{array}{l}\text { Decision confidence } \\
\quad \text { (confidence) }\end{array}$} & Overall & 5.359 & 1.068 & \multirow[t]{4}{*}{4.443} & \multirow[t]{4}{*}{$.050^{*}$} \\
\hline & Compatible & 5.570 & 0.909 & & \\
\hline & Incompatible & 5.010 & 1.218 & & \\
\hline & Neutral & 5.420 & 1.036 & & \\
\hline \multirow{4}{*}{$\begin{array}{l}\text { Product satisfaction } \\
\text { (product) }\end{array}$} & Overall & 4.848 & 1.283 & \multirow[t]{4}{*}{1.292} & \multirow[t]{4}{*}{.277} \\
\hline & Compatible & 4.810 & 1.290 & & \\
\hline & Incompatible & 4.800 & 1.313 & & \\
\hline & Neutral & 5.310 & 1.071 & & \\
\hline \multirow{4}{*}{$\begin{array}{c}\text { Trial experience satisfaction } \\
\text { (experience) }\end{array}$} & Overall & 5.167 & 1.167 & \multirow[t]{4}{*}{1.803} & \multirow[t]{4}{*}{.168} \\
\hline & Compatible & 5.162 & 1.263 & & \\
\hline & Incompatible & 5.072 & 1.012 & & \\
\hline & Neutral & 5.609 & 1.076 & & \\
\hline \multirow{4}{*}{$\begin{array}{l}\text { Purchase intention } \\
\text { (purchase) }\end{array}$} & Overall & 3.380 & 1.489 & \multirow[t]{4}{*}{1.508} & \multirow[t]{4}{*}{.220} \\
\hline & Compatible & 3.364 & 1.458 & & \\
\hline & Incompatible & 3.256 & 1.479 & & \\
\hline & Neutral & 4.021 & 1.671 & & \\
\hline
\end{tabular}

Table 4. Parameter Estimation

\begin{tabular}{|c|c|c|}
\hline CSR compatibility: group comparison & B & Sig. \\
\hline Neutral vs. compatible & -.127 & .659 \\
\hline Incompatible vs. compatible & -.503 &. $\mathbf{0 0 3}{ }^{\text {*** }}$ \\
\hline${ }^{*}$ significant at $.05 ;{ }^{* *}$ significant at $.01 ;{ }^{* * *}$ significant at .005 \\
\hline
\end{tabular}


Table 5. Results of Hypothesis Testing

\begin{tabular}{|c|c|c|c|c|c|}
\hline \multicolumn{2}{|c|}{ Hypothesis } & F value / coefficient & SE & $\mathbf{P}$ & Supported? \\
\hline \multicolumn{2}{|c|}{ H1: CSE compatibility to confidence } & 4.443 & & $<.05$ & Yes \\
\hline \multicolumn{2}{|c|}{$\begin{array}{l}\mathrm{H} 2 \text { : moderating effect of confidence on the } \\
\text { relationship between product satisfaction and } \\
\text { purchase intention }\end{array}$} & 0.099 & 0.021 & $<.001$ & Yes \\
\hline \multicolumn{2}{|c|}{$\begin{array}{l}\text { H3: moderating effect of confidence on the } \\
\text { relationship between experience satisfaction } \\
\text { and purchase intention }\end{array}$} & -0.05 & 0.021 & $<.05$ & $\begin{array}{c}\text { No. } \\
\text { Opposite }\end{array}$ \\
\hline \multirow[t]{6}{*}{ Control variables } & Gender & -0.199 & 0.201 & NS & \\
\hline & Age & -0.149 & 0.109 & NS & \\
\hline & Education & -0.31 & 0.149 & $<.05$ & \\
\hline & Internet experience & -0.039 & 0.032 & NS & \\
\hline & $\begin{array}{c}\text { Number of software trials } \\
\text { before this experiment }\end{array}$ & -0.015 & 0.058 & NS & \\
\hline & $\begin{array}{l}\text { Post-trial software } \\
\text { purchase before this } \\
\text { experiment }\end{array}$ & -0.038 & 0.304 & NS & \\
\hline $\mathbf{R}^{2}$ & DV $=$ purchase & \multicolumn{4}{|c|}{0.1847} \\
\hline
\end{tabular}

\section{Discussion}

\subsection{Findings}

This study highlights the role of CSRs as information search strategies and examines its influence on forming decision confidence on post-trial software purchase decisions. Decision confidence is an important outcome of the trial process and can significantly reduce a user's perceived product uncertainty (Smith et al., 1991; Smith \& Swinyard, 1988). Decision confidence goes beyond product-related factors such as usefulness and is an influential factor in post-trial decision making even when it only functions subconsciously (Buchanan \& O'Connell, 2006; Goodwin, 2009; Kepecs et al., 2008; Wan et al., 2009). In this study, we found evidence of the critical role of appropriate (compatible) CSRs on guiding information searches and in forming higher level of decision confidence. Since a software trial task is relatively complex and not well structured for new users, we consider magnitude threshold and representational stability CSRs suitable and compatible for software trials. The results show that a user's decision confidence was higher when they applied compatible CSRs than neutral CSRs or incompatible CSRs $(\mathrm{H} 1$ supported). In other words, as long as consumers employed compatible CSRs, they can enhance their decision confidence compared to if they used only incompatible CSRs. The finding strongly supports our idea that, for loosely structured and complex tasks such as purchase decisions concerning new software, compatible information search strategies can better assistant someone in accumulating complete and accurate information, especially when a particular task involves critical decision making. Moreover, we found that decision confidence positively moderated the relationship between product satisfaction and purchase intention ( $\mathrm{H} 2$ supported). To put it differently, the more users are confident with their decision, the more satisfied they are with the software and the more inclined they are to purchase it. We could also say that decision confidence promotes the purchase decision given the satisfaction with the software product. This positive enhancement of decision confidence agrees with the findings in others' work such as Dhar and Nowlis (1999).

Surprisingly, decision confidence significantly but negatively moderated the relationship between satisfaction with the trial experience and purchase intention (opposite to H3). Thus, when a user is more confident with the purchase decision (e.g. "I was absolutely right to buy this software" or "I was absolutely right not to buy it"), the effect of subjective feelings toward the trial experience becomes less influential to the purchase decision. The finding of the negative moderating effects suggests that decision confidence may function differently when applied to different user cognitions or perceptions. We believe that a strong decision confidence can mask or cloud the effect of other factors, especially when these factors are less directly associated with the product per se. Scholars have pointed out that direct product experience (such 
as trying the software) is generally viewed as "increasing belief confidence and advantageous" (Li, Daugherty, \& Biocca, 2001, p.15). Looking at the other side of the coin, we may notice that, when one lacks decision confidence ("I'm not sure it's a good idea to buy it now"), a satisfactory trial experience can better inform the purchase decision and should not be neglected. In other words, when someone is not certain with the decision, they are more likely to direct their attention to the experience (such as the smooth trial process and the interactive feedback from the software), which may lead them to make a purchase later.

Although we focus on software trial as a particular type of product trial in this study, we believe that one can generalize the results to other contexts, such as other types of virtual products or physical products provided through online channels. However, we also caution the possibility of mixing the unique characteristics of software with those of other product types because differences may exist in that some software products require purchase to continue usage while some other virtual products may be free to use, which may impact a user's trial behavior and decision making patterns. In addition, trying a physical product (e.g., dish detergent) is usually a one-time initiative and may not enable substantive evaluation during a short period of time. These distinctions require additional model validations in various contexts.

\subsection{Theoretical Contributions}

This study investigates frequently neglected issues in software trials: appropriate information search strategies and how they affect decision outcomes. This study makes a few primary theoretical contributions. First, we found that individuals can use CSRs as effective information search strategies in software trials. Specifically, our findings suggest that both magnitude threshold and representational stability are suitable for software trial tasks. Compatible CSRs directly shape a user's decision confidence through its compatibility with the objectives of the software trial task. We believe that such a finding makes novel contributions to the existing literature by confirming and extending the theoretical implications of CSRs in both Browne et al. (2007) and Pitts and Browne's work (2004). We illuminate the role and effects of different types of CSRs in assisting decision making during a software trial by finding that users try to collect information in a flexible and free manner to avoid overlooking any useful and important function of the software. By applying magnitude threshold and representational stability CSRs, a user can stop the information search when reaching a certain level of information richness or establishing stability in mental satisfaction. In addition, when a consumer evaluates a product to make a purchase decision, complete and correct information usually leads to more secure and certain psychological feelings (Pitts \& Browne, 2004). Previous studies have found that decision confidence increases along with the quantity of relevant information (Zmud, 1979) even if a user may acquire more information than what is economically justified or what is considered to be necessary (Connolly \& Thorn, 1987). Similarly, in our study, we found that magnitude threshold and representational stability CSRs had a higher degree of compatibility with the software trial task than mental list or single criterion CSRs.

In addition, our theoretical model advances our knowledge of the importance of software product trials. Most literature emphasizes the economic value of software trials (Cheng \& Tang, 2010; Jiang, 2010; Wang \& Zhang, 2009) or the design of software trial such as trial restrictions (Cheng \& Liu, 2012; Dey et al., 2013; Wang et al., 2013). We took a unique approach by examining the effects of a user's trial strategies and the way in which the strategies affect users' decision making. Through its theoretical development, this study fills a void such that, in addition to the typical software evaluation (e.g., user satisfaction), certain less visible factors such as compatible or incompatible trial strategies are also influential to trial outcomes.

In particular, we extend the nomological net of post-trial software purchase intention by incorporating the CSRs as information search strategies into the well-established satisfaction paradigm. Based on our findings, compatible CSRs help shaping users' decision confidence, which then augments their decision to purchase the software given that they are satisfied with the software product. Our results provide directions for rethinking the role of decision confidence in the product satisfaction model and its antecedents. Prior research has also suggested that decision makers are often overconfident when making purchase decisions (Ariely, 2000; Hoch \& Ha, 1986; Pereira, 2001). Their ability to control information during their experience with a product, such as a decision making tool, can create an "illusion of control" that creates overconfidence when judging a product's effectiveness (Xiao \& Benbasat, 2007). Therefore, users likely become somewhat overconfident about the product's quality, which makes the trial experience less influential on their purchase decision. More importantly, we should notice the intricacy of such an interplay. In a situation where one has not yet established decision confidence, the positive trial 
experience can possibly champion the influence on purchasing the software and provide a different yet effective channel for the further promotion of the product.

Last but not least, software products have many aspects in common with other products such as those in the electronic commerce contexts and physical products that mimic its process of trail experiences. Thus, one can generalize our findings to broader contexts, and they add to the body of literature on product trials in general.

\subsection{Practical Implications}

From a practical standpoint, our findings help improve our understanding about the software trial process and, thus, offer valuable insights to practice. For example, by understanding how users apply different CSRs, software companies can support and facilitate the trial process to help users achieve their goals with confident decisions (Barkhi, 2001). In turn, the heightened decision confidence will enhance a user's willingness to acquire the software. Based on our findings, we suggest some specific practical implications.

First and foremost, our results can inform software designers and vendors who are generally unaware of the compatible cognitive stopping rules so they can best assist users who are trying their software. Based on our findings, vendors should consider approaches to educate users about the representational stability and difference threshold rules and provide means to encourage them to adopt these rules. Many software users may not be familiar with these mental rules. Thus, vendors should consider explicit training in applying the representational stability and difference threshold rules. Users need to understand that these stopping rules can provide important structuring to their testing the software. For instance, vendors may suggest users to "try as many functions of the software as possible until you are sure you reach a stable level of understanding of the software" (using the representational stability rule) and "try as many functions of the software until you are learning nothing new" (using the difference threshold rule). To assist users' learning through these two types of CSRs, vendors can design a comprehensive and systemic training plan to guide them to go through several steps of evaluating their software and cover all the necessary aspects of doing so. By following the training plan, users will feel better directed to learn with maximum effort and not get lost throughout the software trial evaluation process because it lacks sufficient clues to ensure they can effectively evaluate it. Such plans would help formalize the use of specific techniques derived from the two stopping rules when individuals mentally organize and comprehend information of the software and evaluate it. Such plans should greatly enhance users' experience when trying software and help them become confident with their decisions about it.

Second, emphasizing good software quality and satisfactory trial experience should be the priority in providing a software product. Our study shows that one needs to channel users' attention based on their decision confidence to increase the likelihood that they will purchase the software program in question. In other words, software vendors need to understand the level of decision confidence and then direct users' attention to either the software product or the trial experience. Generally, software vendors should always aim to deliver a high-quality software product, which is the foundation of making software trial initiatives successful. One can ensure one makes such a product through the lifecycle of software design and development, which falls outside our scope here. More importantly, software vendors should note that, when users are very confident with their own decisions, their satisfaction with a software product will increase the chance they will purchase it. Thus, overall, decision confidence augments individuals' purchase decision based on a software product's high quality. Vendors should highlight the unique and superior features of the software as much as possible, which can occur before, during, and even after the trial. However, if a user fails to develop strong decision confidence, the user's trial experience satisfaction will have a weaker impact on the decision to purchase the software.

To improve the effectiveness of software trials, we suggest an "UI intervention" approach. Software vendors can develop and deploy interval checking points (interventions) during the trial. For instance, after the user has interacted with a software program for a while, a question could pop-up on the screen to detect the user's decision confidence by asking: "Are you comfortable to make a decision now to buy the software?". The user needs to provide an answer before moving forward. One can measure the level of decision confidence with low (not at all), medium (maybe), and high (absolutely) or a similar scale. If the user is confident to move onto the decision, the user interface can highlight the strength of the software and promote the purchase option. If, on the other hand, the user is not yet confident to make a decision (low confidence), the programmed intervention can remind the user of the pleasant trial experience as a follow-up such as: "We are glad that your trial is going well. Please take your time to evaluate the 
software.". Thus, the intervention directs the user's attention to the enjoyable experience and augments the likelihood that the user will buy the software.

Despite the means we discuss above to help with purchase decisions, note that, based on our findings, listing one or a few criteria for a user to evaluate part of the software may not be an effective approach because the mental list and single criterion CSRs are not suitable strategies for software trial tasks. When users try to understand every aspect of a software program to make a purchase decision, the feeling of having limited or incomplete information makes them less certain about their judgment on the software's quality or the trial experience because they need more information to make a firm conclusion. Thus, compromised decision confidence will affect a user's decision about purchasing a software program even if the user is satisfied with the software product and trial experience.

To summarize, in this study, we verify the validity of information search strategies and their effects in the software trial context. Our findings assist software vendors in understanding the predisposing factors and consequences of decision confidence when applied to different information searching strategies in special situations. Our findings also advance the development of effective guidance that software vendors can provide to heighten trial users' decision confidence by applying appropriate information search strategies.

\subsection{Limitations and Future Research}

As with any study, ours has several limitations. First, we focused on a specific target: a free trial version of a software program, which may not fully reflect the features or desirability of other software such as websites and digital services. We encourage future research to apply the theoretical foundation in this study to other digital products or services. Second, we conducted the experiment with university students in a controlled laboratory setting with a preselected online software program, which may limit its explanatory power for other populations such as working adults. However, we believe that the student sample shares multiple similarities with a working adult sample in the context of using computer software (e.g., software evaluation criteria or software purchase decision making rules), which helps reduce the potential sample bias. Third, we suggest additional analysis by applying different weights on the indicators used to categorize CSRs into compatible, incompatible, or mix software trial strategies, which may highlight the importance of some indicators compared to others. Fourth, other user decision making outcome measures that we did not capture in this study, such as the total decision time, should be considered as measures to reflect the effectiveness of software trial strategies (Pleskac \& Busemeyer, 2010). Lastly, we recognize the need to work with practitioners to further investigate how software companies can understand which stopping rules to apply and in what situation given varying characteristics of users and the software products themselves. We need future studies to address these limitations, extend the current findings, and further generalize the theoretical implications.

\section{Conclusion}

Inspired by discussions on the role of the decision making process in people's decisions, we used a controlled experiment to investigate the effects of decision confidence on post-trial software purchase decision making. Our findings show that magnitude threshold and representational stability are compatible CSRs for software trial tasks. We found that applying the two compatible CSRs can increase a user's decision confidence, which, in turn, facilitates the individual's post-trial purchase decision making. With software trials' becoming an increasingly common and important aspect crucial to the prosperity of the software market (Cheng \& Liu, 2012; Wang et al., 2013), we hope to advance our understanding of the decision process involved in software trials that influence whether individuals purchase the full software or not.

\section{Acknowledgments}

This research was financially supported by National Natural Science Foundation of China (Grant number: 71572079, 71102039, 71372035), Major Program of National Social Science Foundation of China (15ZDB126) and was sponsored by Qing Lan Project, Jiangsu, China. 


\section{References}

Aaker, J. L., \& Lee, A. Y. (2006). Understanding regulatory fit. Journal of Marketing Research, 43(1), 1519.

Adya, M., \& Francis, M. M. (2011). Can extended exposure to new technology undermine its acceptance? Evidence from system trials of an enterprise implementation. Communications of the Association for Information Systems, 29, 259-278.

Ariely, D. (2000). Controlling the information flow: Effects on consumers' decision making and preferences. Journal of Consumer Research, 27(2), 233-248.

Avnet, T., \& Higgins, E. T. (2003). Locomotion, assessment, and regulatory fit: value transfer from "how" to "what". Journal of Experimental Social Psychology, 39(5), 525-530.

Avnet, T., \& Higgins, E. T. (2006). How regulatory fit affects value in consumer choices and opinions. Journal of Marketing Research, 43(1), 1-10.

Barkhi, R. (2001). The effects of decision guidance and problem modeling on group decision-making. Journal of Management Information Systems, 18(3), 259-282.

Beach, L. R., \& Mitchell, T. R. (1978). A contingency model for the selection of decision strategies. Academy of Management Review, 3(3), 439-449.

Bem, D. J. (1967). Self-perception: An alternative interpretation of cognitive dissonance phenomena. Psychological Review, 74(3), 183-200.

Benlian, A., Titah, R., \& Hess, T. (2012). Differential effects of provider recommendations and consumer reviews in e-commerce transactions: An experimental study. Journal of Management Information Systems, 29(1), 237-272.

Bolton, R. N., \& Lemon, K. N. (1999). A dynamic model of customers' usage of services: Usage as an antecedent and consequence of satisfaction. Journal of Marketing Research, 36(2), 171-186.

Browne, G. J., \& Pitts, M. G. (2004). Stopping rule use during information search in design problems. Organizational Behavior and Human Decision Processes, 95(2), 208-224.

Browne, G. J., Pitts, M. G., \& Wetherbe, J. C. (2007). Cognitive stopping rules for terminating information search in online tasks. MIS Quarterly, 31(1), 89-104.

Buchanan, L., \& O'Connell, A. (2006). A brief history of decision making. Harvard Business Review, 84(1), $32-41$.

Busemeyer, J. R., \& Rapoport, A. (1988). Psychological models of deferred decision making. Journal of Mathematical Psychology, 32(2), 91-143.

Chandrashekaran, M., Rotte, K., Tax, S. S., \& Grewal, R. (2007). Satisfaction strength and customer loyalty. Journal of Marketing Research, 44(1), 153-163.

Cheng, H. K., \& Liu, Y. (2012). Optimal software free trial strategy: The impact of network externalities and consumer uncertainty. Information Systems Research, 23(2), 488-504.

Cheng, H. K., \& Tang, Q. C. (2010). Free trial or no free trial: Optimal software product design with network effects. European Journal of Operational Research, 205(2), 437-447.

Chernev, A. (2004). Goal orientation and consumer preference for the status quo. Journal of Consumer Research, 31(3), 557-565.

Chernev, A. (2009). Choosing versus rejecting: The impact of goal-task compatibility on decision confidence. Social Cognition, 27(2), 249-260.

Cohen, J. (1960). A coefficient of agreement for nominal scales. Educational and Psychological Measurement, 20, 37-46.

Connolly, T., \& Thorn, B. K. (1987). Predecisional information acquisition: Effects of task variables on suboptimal search strategies. Organizational Behavior and Human Decision Processes, 39(3), 397416. 
Daugherty, T., Li, H., \& Biocca, F. (2008). Consumer learning and the effects of virtual experience relative to indirect and direct product experience. Psychology \& Marketing, 25(7), 568-586.

Davies, S. P. (2003). Initial and concurrent planning in solutions to well-structured problems. Quarterly Journal of Experimental Psychology, 56(7), 1147-1164.

Dey, D., Lahiri, A., \& Liu, D. (2013). Consumer learning and time-locked trials of software products. Journal of Management Information Systems, 30(2), 239-267.

Dhar, R. (1997). Consumer preference for a no-choice option. Journal of Consumer Research, 24(2), 215231.

Dhar, R., \& Nowlis, S. M. (1999). The effect of time pressure on consumer choice deferral. Journal of Consumer Research, 25(4), 369-384.

Duan, W. J., Gu, B., \& Whinston, A. B. (2009). Informational cascades and software adoption on the Internet: An empirical investigation. MIS Quarterly, 33(1), 23-48.

Everard, A., \& Galletta, D. F. (2005). How presentation flaws affect perceived site quality, trust, and intention to purchase from an online store. Journal of Management Information Systems, 22(3), 5595.

Fischer, I., \& Budescu, D. V. (2005). When do those who know more also know more about how much they know? The development of confidence and performance in categorical decision tasks. Organizational Behavior and Human Decision Processes, 98(1), 39-53.

Gallaugher, J. M., \& Wang, Y. M. (2002). Understanding network effects in software markets: Evidence from Web server pricing. MIS Quarterly, 26(4), 303-327.

Gefen, D., Straub, D. W., \& Boudreau, M. C. (2000). Structural equation modeling and regression: Guidelines for research practice. Communications of the Association for Information Systems, 4, 170.

Goldstein, D. G., \& Gigerenzer, G. (1999). The recognition heuristic: How ignorance makes us smart. In G. Gigerenzer \& P. M. Todd (Eds.), Simple heuristics that make us smart (pp. 37-58). Oxford, UK: Oxford University Press.

Gigerenzer, G., \& Todd, P. M. (1999). Simple heuristics that make us smart. Oxford, UK: Oxford University Press.

Goodwin, P. (2009). Common sense and hard decision analysis: Why might they conflict? Management Decision, 47(3), 427-440.

Gray, P., \& Hovav, A. (2008). From hindsight to foresight: Applying futures research techniques in information systems. Communications of the Association for Information Systems, 22, 211-234.

Hansen, F. (1972). Consumer choice behavior: A cognitive theory. New York: The Free Press.

Hausmann, D., \& Läge, D. (2008). Sequential evidence accumulation in decision making: The individual desired level of confidence can explain the extent of information acquisition. Judgment and Decision Making Journal, 3(3), 229-243.

Heereman, J., \& Walla, P. (2011). Stress, uncertainty and decision confidence. Applied Psychophysiology and Biofeedback, 36(4), 273-279.

Heitmann, M., Lehmann, D. R., \& Herrmann, A. (2007). Choice goal attainment and decision and consumption satisfaction. Journal of Marketing Research, 44(2), 234-250.

Higgins, E. T., Idson, L. C., Freitas, A. L., Spiegel, S., \& Molden, D. C. (2003). Transfer of value from fit. Journal of Personality and Social Psychology, 84(6), 1140-1153.

Hill, B. (2013). Confidence and Decision. Games and Economic Behavior, 82, 675-692.

Hoch, S. J., \& Ha, Y. W. (1986). Consumer learning: Advertising and the ambiguity of product experience. Journal of Consumer Research, 13(2), 221-233.

Jiang, Z., \& Benbasat, I. (2007). The effects of presentation formats and task complexity on online consumers' product understanding. MIS Quarterly, 31(3), 475-500. 
Jiang, Z. (2010). How to give away software with successive versions. Decision Support Systems, 49(4), 430-441.

Kasper, G. M. (1996). A theory of decision support system design for user calibration. Information Systems Research, 7(2), 215-232.

Kempf, D. S. (1999). Attitude formation from product trial: Distinct roles of cognition and affect for hedonic and functional products. Psychology \& Marketing, 16(1), 35-50.

Kepecs, A., Uchida, N., Zariwala, H. A., \& Mainen, Z. F. (2008). Neural correlates, computation and behavioural impact of decision confidence. Nature, 455(7210), 227-231.

Kogut, C. A. (1990). Consumer search behavior and sunk costs. Journal of Economic Behavior and Organization, 14(3), 381-392.

Koriat, A., Lichtenstein, S., \& Fischhoff, B. (1980). Reasons for confidence. Journal of Experimental Psychology: Human Learning and Memory, 6(2), 107-118.

Krishnan, H., \& Smith, R. (1998). The relative endurance of attitudes, confidence, and attitude-behavior consistency: The role of information source and delay. Journal of Consumer Psychology, 7(3), 273298.

Kruglanski, A. W. (2006). The nature of fit and the origins of 'feeling right': A goal-systemic perspective. Journal of Marketing Research, 43(1), 11-14.

Kvidera, S., \& Koutstaal, W. (2008). Confidence and decision type under matched stimulus conditions: Overconfidence in perceptual but not conceptual decisions. Journal of Behavioral Decision Making, 21(3), 253-281.

Laroche, M., Kim, C., \& Zhou, L. (1996). Brand familiarity and confidence as determinants of purchase intention: An empirical test in a multiple brand context. Journal of Business Research, 37(2), 115120.

Lee, Y., \& Tan, Y. (2013). Effects of different types of free trials and ratings in sampling of consumer software: An empirical study. Journal of Management Information Systems, 30(3), 213-246.

Li, H., Daugherty, T., \& Biocca, F. (2001). Characteristics of virtual experience in electronic commerce: A protocol analysis. Journal of Interactive Marketing, 15(3), 13-30.

Lippman, S. A., \& McCall, J. (1976). The economics of job search: A survey. Economic Inquiry, 14(2), 155-189.

McKinney, V., Yoon, K., \& Zahedi, F. (2002). The measurement of web-customer satisfaction: An expectation and disconfirmation approach. Information Systems Research, 13(3), 296-315.

Meyer, R. J., \& Sathi, A. (1985). A multiattribute model of consumer choice during product learning. Marketing Science, 4(1), 41-61.

Mittal, V., \& Kamakura, W. A. (2001). Satisfaction, repurchase intent, and repurchase behavior: Investigating the moderating effect of customer characteristics. Journal of Marketing Research, $38(1), 131-142$.

Moore, D. A., Carter, A. B., \& Yang, H. H. J. (2015). Wide of the mark: Evidence on the underlying causes of overprecision in judgment. Organizational Behavior and Human Decision Processes, 131, 110120.

Morera, O. F., \& Budescu, D. V. (1998). A psychometric analysis of the "divide and conquer" principle in multicriteria decision making. Organizational Behavior and Human Decision Processes, 75(3), 187206.

Parker, J. R., Lehmann, D. R., \& Yi, X. (2016). Decision comfort. Journal of Consumer Research, 43(1), 113-133.

Pereira, R. E. (2001). Influence of query-based decision aids on consumer decision making in electronic commerce. Information Resources Management Journal, 14(1), 31-48.

Pitts, M. G., \& Browne, G. J. (2004). Stopping behavior of systems analysts during information requirements elicitation. Journal of Management Information Systems, 21(1), 203-226. 
Pleskac, T. J., \& Busemeyer, J. R. (2010). Two-stage dynamic signal detection: A theory of choice, decision time, and confidence. Psychological Review, 117(3), 864-901.

Podsakoff, P. M., MacKenzie, S. B., Lee, J. Y., \& Podsakoff, N. P. (2003). Common method biases in behavioral research: a critical review of the literature and recommended remedies. Journal of Applied Psychology, 88(5), 879.

Porter, A. M. (2004). The case for holistic strategies. Purchasing, 133(5), 55-59.

Rathnam, G. (2005). Interaction effects of consumers' product class knowledge and agent search strategy on consumer decision making in electronic commerce. IEEE Transactions on Systems, Man and Cybernetics, Part A: Systems and Humans, 35(4), 556-573.

Ross, M., \& Shulman, R. F. (1973). Increasing the salience of initial attitudes: Dissonance versus selfperception theory. Journal of Personality and Social Psychology, 28(1), 138-144.

Schlereth, C., Barrot, C., \& Skiera, B. (2013). Optimal product-sampling strategies in social networks: How many and whom to target? International Journal of Electronic Commerce, 18(1), 45-72.

Shafir, E., Simonson, I., \& Tversky, A. (2000). Reason-based choice. In D. Kahneman \& A. Tversky (Eds.), Choice, values and frames (pp. 597-619). New York: Cambridge University Press.

Sharp, G. L., Cutler, B. L., \& Penrod, S. D. (1988). Performance feedback improves the resolution of confidence judgments. Organizational Behavior and Human Decision Processes, 42(3), 271-283.

Smith, G. F., Benson, P. G., \& Curley, S. P. (1991). Belief, knowledge, and uncertainty: A cognitive perspective on subjective probability. Organizational Behavior and Human Decision Processes, 48(2), 291-321.

Smith, R. E., \& Swinyard, W. R. (1982). Information response models: An integrated approach. Journal of Marketing, 46(1), 81-93.

Smith, R. E., \& Swinyard, W. R. (1988). Cognitive response to advertising and trial: Belief strength, belief confidence and product curiosity. Journal of Advertising, 17(3), 3-14.

Stigler, G. J. (1961). The economics of information. Journal of Political Economics, 69(3), 213-225.

Successful Software. (2009). The truth about conversion rations for downloadable software. Retrieved from https://successfulsoftware.net/2009/04/23/the-truth-about-conversion-ratios-for-software/.

Tan, W. K., Tan, C. H., \& Teo, H. H. (2012). Consumer-based decision aid that explains which to buy: Decision confirmation or overconfidence bias? Decision Support Systems, 53(1), 127-141.

Tu, Y., \& Lu, M. (2006). An experimental and analytical study of on-line digital music sampling strategies. International Journal of Electronic Commerce, 10(3), 39-70.

Urbach, N., \& Ahlemann, F. (2010). Structural equation modeling in information systems research using partial least squares. Journal of Information Technology Theory and Application, 11(2), 5-40.

Vakkari, P. (1999). Task complexity, problem structure and information actions: Integrating studies on information seeking and retrieval. Information Processing and Management, 35(6), 819-837.

Vickers, D. (1979). Decision processes in visual perception. New York: Academic Press.

Wan, E. W., Hong, J., \& Sternthal, B. (2009). The effect of regulatory orientation and decision strategy on brand judgments. Journal of Consumer Research, 35(6), 1027-1039.

Wang, H., \& Liu, Y. (2014). Effect of compatibility between decision target and processing strategy on postdecision satisfaction. Social Behavior and Personality, 42(3), 423-435.

Wang, T., Oh, L. B., Wang, K., \& Yuan, Y. (2013). User adoption and purchasing intention after free trial: An empirical study of mobile newspapers. Information Systems and e-Business Management, 11(2), 189-210.

Wang, C. A., \& Zhang, X. M. (2009). Sampling of information goods. Decision Support Systems, 48(1), 14-22.

Wehner, M. C., Giardini, A., \& Kabst, R. (2012). Graduates' reactions to recruitment process outsourcing: A scenario-based study. Human Resource Management, 51(4), 601-623. 
Wixom, B. H., \& Todd, P. A. (2005). A theoretical integration of user satisfaction and technology acceptance. Information Systems Research, 16(1), 85-102.

Wood, R. E. (1986). Task complexity: Definition of the construct. Organizational Behavior and Human Decision Processes, 37(1), 60-82.

Xiao, B., \& Benbasat, I. (2007). E-commerce product recommendation agents: Use, characteristics, and impact. MIS Quarterly, 31(1), 137-209

Yang, X., Schiller, S., Teo, H. H., \& Wang, Q. S. (2010). Are you doing it in the right way? The effects of regulatory fit in IT product trial. In Proceedings of the 4th China Summer Workshop on Information Management.

Yang, X. \& Teo, H. H. (2007). How do users cope with trial restrictions? A longitudinal field experiment on free trial software. In Proceedings of the 28th International Conference on Information Systems.

Yang, X., Teo. H. H., \& Tan, C. H. (2006). A psychological reactance perspective on time and functionality restriction of free trial software: Are you willing to evaluate the software? in Proceeding of the Twenty-Seventh International Conference on Information Systems (ICIS), Milwaukee, WI, USA, December $10^{\text {th }}-13^{\text {th }}, 1509-1528$.

Yates, J. F. (1990). Judgment and decision making. Englewood Cliffs, NJ: Prentice Hall.

Yeung, N., \& Summerfield, C. (2012). Metacognition in human decision-making: Confidence and error monitoring. Philosophical Transactions of the Royal Society B: Biological Sciences, 367(1594), 1310-1321.

Zmud, R. W. (1979). Individual differences and MIS success: A review of the empirical. Management Science, 25(10), 966-979. 


\section{Appendix A}

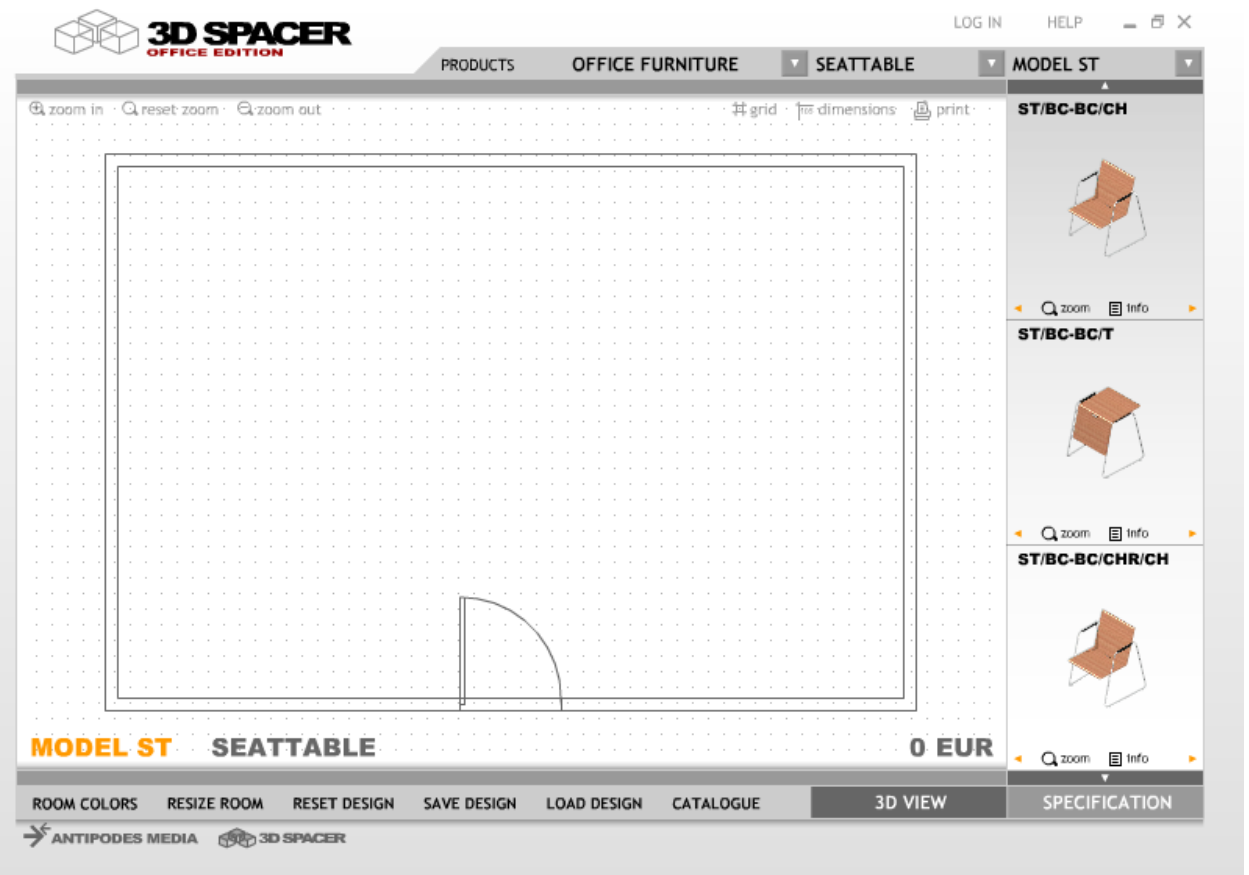

Figure A1. Design Interface of the Online Interior Design Software and 2D/3D Design Samples

3D SPACER

LOG IN HELP - I $\times$

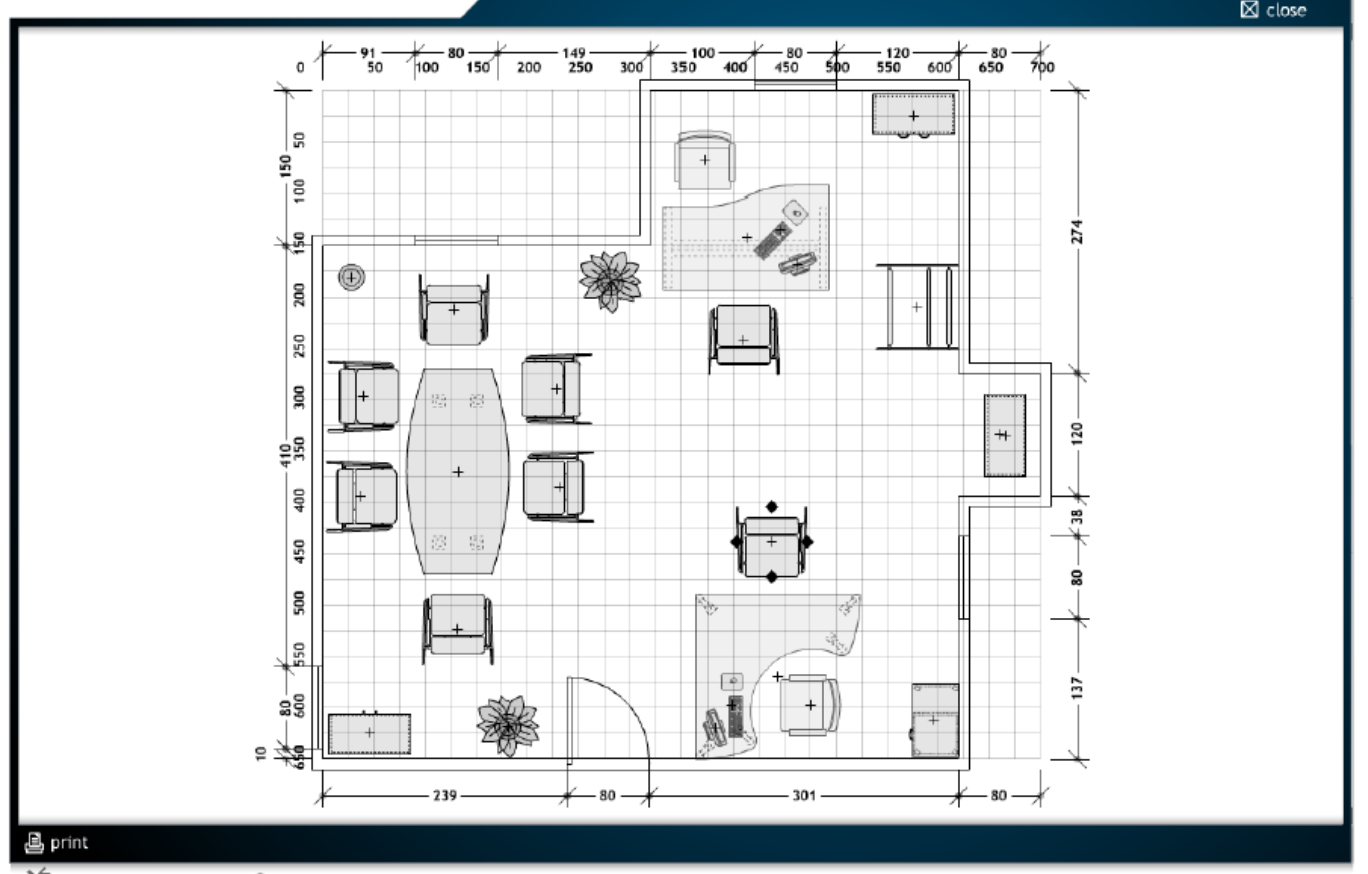

$\rightarrow$ ANTIPODES MEDIA 3D SPACER

Figure A2. Design Interface of the Online Interior Design Software and 2D/3D Design Samples 


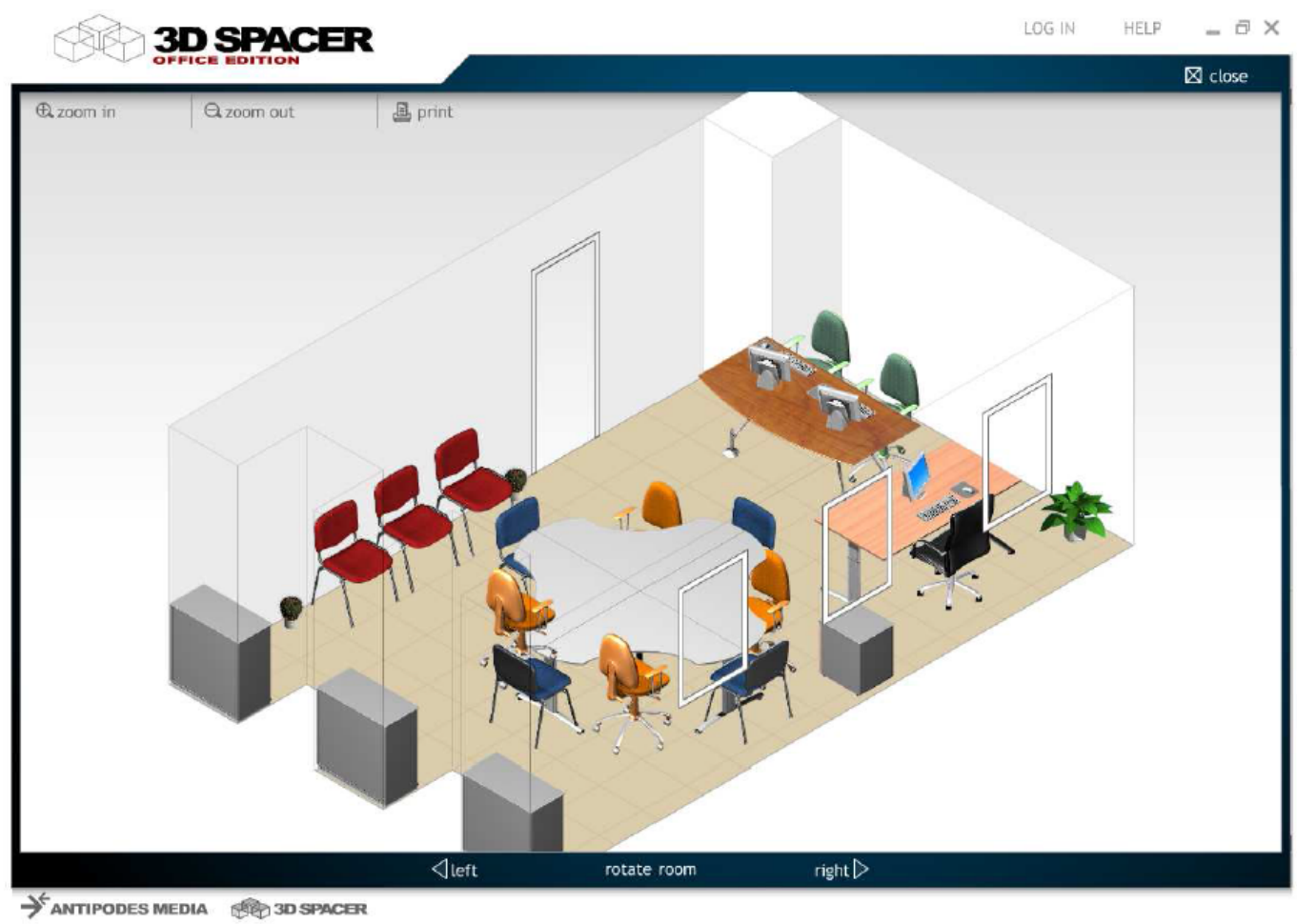

Figure A3. Design Interface of the Online Interior Design Software and 2D/3D Design Samples 


\section{About the Authors}

Xue Yang is an associate professor in the Department of Marketing and Electronic Business, School of Business (Management), Nanjing University (NJU), China. She received her PhD in Information Systems from National University of Singapore (NUS). Her current research interests include free trial software and product impacts, social network effects in e-commerce, mobile application design and $\mathrm{HCl}$ and spontaneous virtual team. Her research work has appeared in journals such as Journal of the Association for Information Systems, Information \& Management, Decision Support Systems, IEEE Transaction on Engineering Management, Business Horizons, among others, as well as various international conferences. She has been a member of Association of Information Systems (AIS) since 2004. She is currently Associate Editor for Electronic Commerce Research, Journal of Global Information Management and Executive Editor for NJU Business Review (Chinese).

Shu Schiller is an Associate Professor of Information Systems in the Raj Soin College of Business at Wright State University. She holds a PhD in Business Administration, Management Information Systems from the Fox School of Business at Temple University. Her research is motivated by the possibilities to improve and advance communication and collaboration in today's highly networked society. Most of her research focuses on computer-mediated communication, virtual teams, digital media, data analytics and visualization, and IT in practice including e-learning. Her works are published in journals such as Small Group Research, Computers in Human Behavior, Communications of the Association for Information Systems, and Information Systems Management.

Hock-Hai Teo is Provost's Chair Professor of Information Systems. He served as the Head of the Department of Information Systems at the School of Computing, National University of Singapore from August 2008 to June 2015 and as Vice-Dean, Corporate Communications from August 2007 to August 2008. His current research interests focus mainly on Health Informatics, open innovation, and IT artifacts that are geared towards improving individual decision-making, health outcomes and educational outcomes. He has published broadly in journals such as the ACM Transactions on Computer-Human Interactions, MIS Quarterly, Journal of Management Information Systems, Information Systems Research, IEEE Transactions on Engineering Management, International Journal of Human-Computer Studies, and Information and Management and has presented at numerous international conferences, including the International Conference on Information Systems. He is currently serving or has served on the editorial boards of Data Base for Advances in Information Systems, European Journal of Information Systems, International Journal of Electronic Commerce, Information Systems Research, IEEE Transactions on Engineering Management and MIS Quarterly. He has won numerous best paper award at conferences and was also the winner of the MIS Quarterly Reviewer of the Year (2004) award.

Quansheng Wang is a Professor of Department of Marketing and Electronic Business and the Vice Dean of School of Management, Nanjing University (NJU), China. He holds a PhD Degree in Business Administration from Nanjing University. His current research focuses on online consumer behavior, internet marketing and WOM, e-Business competitive strategy. He leads recent and current ongoing research projects, titled "An Empirical Study of Consumer Channel Choice Behavior Based on Search and Purchase Stages of Shopping Process" (Project No. 70772035) and "An Experimental Study on the Role of Group Arguments, Refutation and Customer-Company Identification on the Internet Rumor Transmission" (Project No. 71072045), that are funded by the National Natural Science Foundation of China (NSFC). He has published research articles in journals such as Electronic Market and International Journal of Electronic Commerce.

Copyright $@ 2017$ by the Association for Information Systems. Permission to make digital or hard copies of all or part of this work for personal or classroom use is granted without fee provided that copies are not made or distributed for profit or commercial advantage and that copies bear this notice and full citation on the first page. Copyright for components of this work owned by others than the Association for Information Systems must be honored. Abstracting with credit is permitted. To copy otherwise, to republish, to post on servers, or to redistribute to lists requires prior specific permission and/or fee. Request permission to publish from: AIS Administrative Office, P.O. Box 2712 Atlanta, GA, 30301-2712 Attn: Reprints or via email from publications@aisnet.org. 


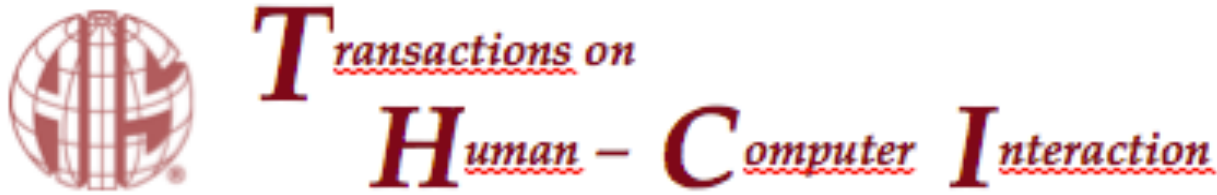

\subsection{Editors-in-Chief}

Dennis Galletta, U. of Pittsburgh, USA http://thci.aisnet.org/

Paul Benjamin Lowry, U. of Hong Kong, China

\subsection{Advisory Board}

\begin{tabular}{|l|l|l|}
\hline $\begin{array}{l}\text { Izak Benbasat } \\
\text { U. of British Columbia, Canada }\end{array}$ & $\begin{array}{l}\text { John M. Carroll } \\
\text { Penn State U., USA }\end{array}$ & $\begin{array}{l}\text { Phillip Ein-Dor } \\
\text { Tel-Aviv U., Israel }\end{array}$ \\
\hline $\begin{array}{l}\text { Jenny Preece } \\
\text { U. of Maryland, USA }\end{array}$ & Gavriel Salvendy, & Ben Shneiderman \\
\hline $\begin{array}{l}\text { Joe Valacich } \\
\text { U of Arizona, USA }\end{array}$ & Purdue U., USA, \& Tsinghua U., China & U. of Maryland, USA \\
\hline
\end{tabular}

Ping Zhang

Syracuse University USA

\subsection{Senior Editor Board}

Torkil Clemmensen

Copenhagen Business School Denmark

Mohamed Khalifa

$U$. Wollongong in Dubai., UAE

Fiona Fui-Hoon Nah

Missouri University of Science and

Technology, USA

Jason Thatcher

Clemson University, USA

Mun Yi

Korea Advanced Ins. of Sci. \&

Tech, Korea

\subsection{Editorial Board}

Miguel Aguirre-Urreta
DePaul U., USA

Michael Davern

Matt Germonprez

U. of Wisconsin Eau Claire, USA

Milena Head

McMaster U., Canada

Weiling $\mathrm{Ke}$

Clarkson U., USA

Scott McCoy

College of William and Mary, USA

Sheizaf Rafaeli

U. of Haifa, Israel

Hong Sheng

Missouri U. of Science and

Technology, USA

Horst Treiblmaier

Vienna U. of Business Admin.\&

Economics, Austria

Fred Davis

U. of Arkansas, USA

Jinwoo Kim

Yonsei U., Korea

Lorne Olfman

Claremont Graduate U., USA

Noam Tractinsky

Ben-Gurion U. of the Negev, Israel
Traci Hess

U. of Massachusetts Amherst, USA

Eleanor Loiacono

Worcester Polytechnic Institute,

Kar Yan Tam

Hong Kong U. of Science \&

Technology, China

Viswanath Venkatesh

U. of Arkansas, USA
Shuk Ying (Susanna) Ho

Australian National U., Australia

Anne Massey

Indiana U., USA

Dov Te'eni

Tel-Aviv U., Israel

Susan Wiedenbeck

Drexel University, USA

Meiyun Zuo

Renmin U., China

\subsection{Managing Editor}

Gregory D. Moody, U. of Nevada Las Vegas, USA

1.6 SIGHCI Chairs

\author{
2001-2004: Ping Zhang
}

2007-2008: Weiyin Hong

2011-2012: Dianne Cyr

2017: Zenhui Jiang
Michel Avital Hock Chuan Chan

Copenhagen Business School, National U. of Singapore,

Denmark

Carina de Villiers

U. of Pretoria, South Africa

Jennifer Gerow

Virginia Military Institute, USA

Netta livari

Oulu U., Finland

Sherrie Komiak

Memorial U. of Newfoundland,

Canada

Gregory D. Moody

U. of Nevada Las Vegas, USA

Rene Riedl

Johannes Kepler U. Linz, Austria

Stefan Smolnik

European Business School,

Germany

Ozgur Turetken

Ryerson U., Canada
Singapore

Alexandra Durcikova

U. of Arizona, USA

Suparna Goswami

Zhenhui Jack Jiang

National U. of Singapore,

Singapore

$\mathrm{Na} \mathrm{Li}$

Baker College, USA

Robert F. Otondo

Mississippi State U., USA

Khawaja Saeed

Wichita State U., USA

Jeff Stanton

Syracuse U., USA

Fahri Yetim

U. of Siegen, Germany
Christy M.K. Cheung

Hong Kong Baptist University,

China

Xiaowen Fang

DePaul University

Khaled Hassanein

Manactar II Canoda

Richard Johnson SUNY at Albany, USA

Ji-Ye Mao

Renmin U., China

Lingyun Qiu

Peking U., China

Shu Schiller

Wright State U., USA

Heshan Sun

U. of Arizona, USA

Cheng Zhang

Fudan U., China

\begin{tabular}{|l|l|}
\hline 2004-2005: Fiona Fui-Hoon Nah & 2005-2006: Scott McCoy \\
\hline 2008-2009: Eleanor Loiacono & 2009-2010: Khawaja Saeed \\
\hline 2012-2013: Soussan Djamasbi & 2013-2015: Na Li \\
\hline 2018: Gregory D. Moody & \\
\hline
\end{tabular}

http://sigs.aisnet.org/sighci

2006-2007: Traci Hess

2010-2011: Dezhi Wu

2016: Miguel Aguirre-Urreta 